\title{
Desenvolvimento da autonomia na escrita em língua adicional através do feedback por pares: um relato de experiência
}

\author{
Rafael Zaccaron ${ }^{1}$ \\ Programa de Pós-Graduação em Inglês: Estudos Linguísticos e Literários, Universidade Federal de Santa \\ Catarina, Florianópolis, SC, Brasil
}

Resumo: Tendo por base o conceito de escrita como um processo (HYLAND; HYLAND, 2006), neste relato de experiência², apresento a implementação do processo de feedback por pares na produção escrita realizada na aula de inglês como língua adicional do curso Extracurricular da Universidade Federal de Santa Catarina. Tal movimento visa, a longo prazo, desenvolver a autonomia dos aprendizes e sua criticidade. A sequência de procedimentos para implantação do feedback por pares é apresentada. Esse relato também apresenta alguns dados preliminares de uma pesquisa longitudinal sobre feedback por pares. Respostas dadas pelos participantes, através de um questionário de percepção, são analisadas e relacionadas com o relato. Finalizo com um balanço da atividade apontando os desafios e os benefícios de tal movimento para a sala de aula.

Palavras-chave: Autonomia na escrita; Feedback por pares; Aprendizagem colaborativa; Inglês como língua adicional.

Title: Promoting autonomy in additional language writing through peer feedback: An experience report Abstract: Having the concept of writing as a process (HYLAND; HYLAND, 2006) as a basis, in this experience report, I present the implementation of the peer feedback process for English as additional language writing in the Extracurricular course context at the Federal University of Santa Catarina. Such activity aims, in the long run, to develop learners' autonomy and critical reasoning. The set of procedures for implementing peer feedback is presented, as well as some preliminary data from a longitudinal study on the same topic. Moreover, answers from a perception questionnaire given by participants are analysed and linked to the report, Finally, I weigh the pros and cons of such activity pointing the challenges and benefits for the classroom.

Keywords: Autonomy in writing; Peer feedback; Collaborative learning; English as an additional language.

\footnotetext{
1 Mestre em Inglês: Estudos Linguísticos e Literários (Universidade Federal de Santa Catarina). Orcid: https://orcid.org/0000-0001-7796-501X.

E-mail: rafaelzaccaron@gmail.com

${ }^{2}$ Agradeço a leitura crítica de uma versão preliminar do texto feita pelas colegas Donesca Xhafaj e Milena Noll, bem como as valiosas contribuições das/os revisoras/es anônimas/os.
} 


\section{Introdução}

De acordo com Borg e Al-Busaidi (2012), a autonomia da/o aprendiz tem sido foco de muita discussão teórica nos últimos 30 anos e, em linhas gerais, é indicado que a mesma:

enriquece a qualidade na aprendizagem de língua, promove sociedades democráticas, prepara indivíduos para aprendizado futuro, é um direito humano, e permite que estudantes façam melhor proveito de situações de aprendizado dentro e fora da sala de aula (tradução minha, p. 3$)^{3}$.

Holec (1981), autor que por muitos anos balizou estudos nessa área, advoga pela autonomia completa dos estudantes. Segundo esse autor, são os aprendizes que devem decidir o quê e, de certa forma, como estudar desde as primeiras aulas do grupo. Por outro lado, Sinclair (2000) aponta que a autonomia completa proposta por Holec é um objetivo idealista. Segundo Sinclair, há diversos níveis de autonomia que são variáveis ao longo do processo de aprendizagem. A autora afirma que o desenvolvimento da autonomia requer metacognição - ou seja, a reflexão consciente sobre o próprio processo de aprendizagem - e, portanto, vai além do simples ensino de estratégias em sala de aula. Por fim, Sinclair ressalta ainda que a autonomia envolve tanto aspectos individuais quanto sociais, e reverbera no âmbito psicológico e político. Weininger (2008) defende que a autonomia deve funcionar tanto para professores quanto para aprendizes de uma língua adicional. Assim, são as visões de Borg e Al-Busaidi (2012), Sinclair (2000) e Weininger (2008) sobre autonomia que norteiam o presente relato de experiência sobre o feedback por pares na produção escrita em língua adicional (doravante LA).

Outro conceito-chave para a discussão desse relato é a o termo feedback por pares. De acordo com Liu e Edwards (2018), o feedback por pares tem os aprendizes como fonte de informação e interação, de modo que o papel e as responsabilidades normalmente atribuídos a um/a professor/a passam a ser ocupados pelos aprendizes, uma vez que eles comentam e criticam os trabalhos escritos uns dos outros de forma oral ou escrita.

O desenvolvimento da autonomia é um dos aspectos positivos ressaltados na atividade de feedback por pares na produção escrita (HYLAND; HYLAND, 2006; SHRUM; GLISAM, 2009). Outros aspectos benéficos comumente associados ao feedback por pares são que: (1) pode vir a reduzir a ansiedade na escrita, uma vez que a/o estudante observa pontos fortes e pontos a serem melhorados no texto da/o colega que podem ser semelhantes aos seus (HO; SAVIGNON, 2007; SHRUM; GLISAM, 2009); (2) pode ajudar no desenvolvimento de aquisição da gramática e expandir o repertório lexical (STORCH, 2005); e (3) pode desencadear

\footnotetext{
${ }^{3}$ No original: "it improves the quality of language learning, promotes democratic societies, prepares individuals for life-long learning, that it is a human right, and that it allows learners to make best use of learning opportunities in and out of the classroom." (BORG; AL-BUSAIDI, 2012, p. 3)
} 
processos metalinguísticos envolvidos no processo de olhar o texto de um/a colega (FIGUEIREDO, 2002). Em síntese, ao analisar a produção escrita em LA de um/a colega, a/o estudante pode vir a refletir sobre sua habilidade na escrita, expandir seu repertório sintático e lexical e vir a se tornar mais autônoma/o ao refletir sobre a língua.

Já em uma perspectiva mais tradicional de ensino, que resiste ao tempo e que percebe o texto como produto, é a/o professor/a que detém o saber e é somente ela/e quem pode prover feedback em sala de aula (SHIGUNOV NETO; MACIEL, 2016). Nesse contexto, é relevante questionarmos se usamos na aula de língua adicional formas de avaliação e feedback consolidadas (e de certa forma convencionais) com o propósito de promovermos nossos objetivos pedagógicos, ou se esses instrumentos cumprem apenas a função de propagar e perpetuar o que é visto como papel da/o professor/a.

Com base nesses questionamentos resta a pergunta: qual seria o papel da/o professor/a de LA para fomentar a autonomia de aprendizes na produção escrita? Esse relato tem como principal objetivo socializar a experiência do autor na implementação do feedback por pares na aula de inglês como LA no curso de inglês Extracurricular da Universidade Federal de Santa Catarina (UFSC). Tal relato faz parte de uma pesquisa longitudinal ${ }^{4}$ desenvolvida pelo autor e sua orientadora com o intuito de investigar a relevância de diversas formas de feedback por pares nas aulas de inglês como LA, seu impacto no texto e a percepção dos envolvidos no processo. Dessa forma, extrapola-se o modelo clássico de relato com o intuito de agregar dados que enriqueçam tal discussão.

Mais especificamente, esse relato foca questões de ordem prática sobre a implementação do método e a percepção dos atores - estudantes e professor - envolvidos. Inicialmente apresento aspectos teóricos e estudos que fundamentam o feedback por pares. Nesse movimento, buscam-se evidências de como o feedback por pares pode auxiliar o desenvolvimento da habilidade escrita em LA em um curso de inglês com vistas a desenvolver um/a escritor/a autônoma/o. Na sequência, descrevo o contexto da pesquisa que originou o relato. A seção seguinte traz os passos seguidos para a implementação do feedback por pares na aula de LA e possíveis variações. A percepção dos participantes sobre o processo é apresentada em seguida. Finalmente, são tecidas algumas considerações acerca dos pontos abordados nesse relato.

\section{Feedback por pares da produção escrita em língua adicional}

A perspectiva sociointeracionista (LONG, 2015; SWAIN, 2000) oferece suporte teórico para o desenvolvimento do feedback por pares, pois propõe que na interação que envolve produção há a possibilidade de a atenção dos aprendizes incidir tanto em aspectos macro (i.e.,

\footnotetext{
${ }^{4}$ Essa pesquisa foi aprovada pelo comitê de ética da UFSC em 2017 sob o seguinte protocolo 3.094.021.
} 
a mensagem), quanto em questões micro (i.e., forma) da língua. Swain (2000) aponta que aprendizes podem vir a notar lacunas em seus repertórios linguísticos e, ao produzirem língua, terem sua atenção direcionada do campo semântico para o sintático. É nesse momento em que, através de diálogos colaborativos (SWAIN, 2000; SWAIN; BROOKS; TOCALLI-BELLER, 2002), estudantes podem vir a negociar não somente significado, como também aspectos de forma (LONG, 2015).

Ainda em relação à interação em pares, vale ressaltar que o processo de feedback para a escrita resulta em uma audiência autêntica para o texto (FIGUEIREDO; RIGONATO, 2017), uma vez que a produção textual deixa de ser apenas uma atividade (produto) a ser entregue à/ao professor/a. Assim, a/o escritor/a percebe a necessidade de comunicar suas ideias de forma que a/o colega compreenda seu texto. Tal movimento está alinhado com perspectivas pedagógicas que focam na tarefa, com o uso significativo da língua em sala de aula, e abordagens que focam no papel social do escritor, uma vez que a escrita tem a função de participação social (BEAUFORT, 2000). Segundo Beaufort (2000), no processo de prover e receber feedback, aprendizes podem exercer o papel de: estudante, colaborador/a, observador/a, pesquisador/a etc.

Do ponto de vista pedagógico, alunos têm, geralmente, a expectativa de receber feedback para suas produções escritas e sentem-se frustrados caso isso não aconteça (HYLAND; HYLAND, 2006). Considerando que a escrita demanda processos cognitivos complexos, prover feedback para tal produção é também uma atividade que demanda tempo da/o professor/a, ainda mais quando os grupos de estudantes são numerosos. Ao deslocar o papel da/o expert para provimento de feedback para um/a colega, ocorre uma mudança na relação ensino-aprendizado normalmente percebida na sala de $L A$, bem como um papel mais ativo dos estudantes, que dividem com a/o professor/a a responsabilidade de apreciação de textos escritos pelos colegas. Com base em tal cenário, o feedback por pares mostra-se como uma alternativa atraente ao transferir não somente parte do trabalho, mas, o mais importante, parte das responsabilidades da avaliação e aprendizagem de forma crítica à/ao aprendiz com vistas a desenvolver sua autonomia como escritor/a.

Uma última questão a ser abordada com relação ao feedback para a escrita é a forma como o mesmo é provido: diretamente (quando é apresentada a forma julgada apropriada por quem provê o feedback) ou indiretamente (quando um código, comentário ou sistema de cores sinaliza uma passagem a ser melhorada no texto - e.g., conteúdo, organização, tempo verbal, palavra sobrando, etc. - sem fornecer a solução) (HYLAND; HYLAND, 2006). Por estar alinhado à ideia de escrita como um processo e ao desenvolvimento de processos metacognitivos (i.e., a reflexão sobre a aprendizagem) necessárias ao desenvolvimento da autonomia (SINCLAIR, 2000), o feedback indireto foi escolhido pelo autor como objeto de estudo e é abordado nesse relato de experiência. 


\section{O desenvolvimento da competência escrita em cursos de inglês: $\mathbf{O}$ curso Extracurricular de inglês da UFSC}

Os cursos Extracurriculares fazem parte de um projeto de extensão universitária dentro do departamento de língua e literatura estrangeiras da UFSC. Com mais de 40 anos, os cursos Extracurriculares ofertam uma gama de cursos de línguas adicionais, sendo o curso de inglês o mais procurado (MARTINS; REIS, 2015). O curso é aberto à comunidade externa da UFSC para alunos maiores de 15 anos, oferece turmas desde os níveis iniciantes até níveis avançados e não possui fins lucrativos.

Os professores do curso Extracurricular de inglês são, em sua maioria, alunos do programa de pós-graduação em Inglês da UFSC, sendo que há também alunos de graduação do curso de Letras Inglês. O curso configura-se como uma oportunidade de desenvolvimento profissional e de formação continuada para esses alunos.

Perguntas referentes ao papel do desenvolvimento da escrita em sala de aula pelos professores do curso Extracurricular foram feitas aos dois coordenadores da área de inglês desse curso. Com base nas respostas, percebe-se que a escrita seria a terceira ou quarta habilidade mais trabalhada - dependendo da visão de cada coordenador/a - dentre as quatro habilidades alvo na aula de língua adicional, sendo elas: falar, escrever, ler e ouvir. Como aponta a coordenadora do curso de inglês: "Acredito que a grande maioria dos professores não enfatiza a habilidade da escrita, realizando de forma sucinta as atividades propostas pelos livros didáticos". Tal posicionamento está em consonância com Leandro e Weissheimer (2017), que também indicam que a escrita é uma habilidade que foi, de modo geral, relegada ao segundo plano na abordagem comunicativa do ensino de língua adicional até recentemente.

Apesar do curso Extracurricular adotar livros didáticos como base, a autonomia da/o professor/a em como trabalhar o conteúdo proposto é uma característica do curso. Assim, os coordenadores salientaram que alguns professores trabalham com a produção escrita de forma destacada, em muitos destes casos, por terem afinidade com esta habilidade ou por perceberem o forte interesse dos alunos. Segundo o subcoordenador do curso: "Na minha experiência, os alunos apreciam as oportunidades de desenvolver esta habilidade (escrita), uma vez que ela é menos trabalhada que as outras". No entanto, em função da dedicação e o tempo necessários ao desenvolvimento do processo da escrita tanto por parte dos aprendizes quanto da/o professor/a para o feedback, essa tende a ser, de uma maneira geral, uma das habilidades menos desenvolvidas com os alunos. Sobre a falta de tarefas de escrita em quantidade suficientes a coordenadora do curso salienta: "Uma das razões para isso é que o desenvolvimento da escrita é uma tarefa que implica uma grande dedicação e toma muito tempo tanto do professor como o aluno".

Nesse aspecto, é preciso ressaltar que o autor desse relato é um dos professores que 
valoriza o desenvolvimento da escrita como processo na aula de inglês como LA. Concordo com o subcoordenador do Extracurricular da UFSC e Leandro e Weissheimer (2017), quando os mesmos afirmam que a habilidade de escrita em LA é renegada em cursos de inglês e deve ser trabalhada como as demais habilidades.

\section{A implementação do feedback por pares: Metodologia adotada}

Enquanto a pesquisa na área de feedback por pares em língua adicional mostra aspectos positivos e negativos na sua implantação (CHANG, 2016), um aspecto consolidado na literatura como vital para o sucesso dessa atividade é a necessidade da prática ou treinamento para oferecer tal feedback (HYLAND; HYLAND, 2006; SHRUM; GLISAM, 2009). Tal fato mostra-se pertinente pela experiência do autor como professor no curso Extracurricular. Mais de $85 \%$ dos alunos ao responderem ao questionário de percepção (parte da pesquisa longitudinal) no final do semestre indicam nunca terem tido anteriormente a experiência de prover feedback a um/a colega, não somente na aula de língua adicional, como em qualquer outra disciplina. É necessário considerar que para muitos alunos essa será a primeira oportunidade de ler criticamente o texto de um/a colega e o treinamento para tal é imprescindível.

Tal contexto exige uma preparação com vistas a diminuir a ansiedade dos alunos em prover e receber feedback, uma vez que eles não estão familiarizados com esse processo. Há diversas formas de feedback por pares (como o anônimo, dialogado etc.) ${ }^{5}$ que podem ser desenvolvidas; esse relato, no entanto, foca nas etapas básicas necessárias para implantação de qualquer tipo de feedback indireto por pares na aula de língua adicional, sendo o principal elemento o treinamento.

Para implantar o feedback por pares foram seguidos os seguintes passos: inicialmente uma produção escrita individual, que devia ser enviada para o professor por e-mail ${ }^{6}$, foi requisitada aos estudantes. O feedback nesse primeiro texto foi feito pelo professor, uma vez que esse passo permite que os aprendizes se familiarizem com o feedback indireto por cores e a tabela de comentários ${ }^{7}$, tabela 1 . Desta forma, o primeiro feedback serviu como um modelo para o feedback a ser realizado em pares. As modificações nesse primeiro texto foram, então, realizadas pelos aprendizes considerando o feedback recebido, e a versão final enviada para o professor.

\footnotetext{
${ }^{5}$ Para informações mais detalhadas sobre feedback por pares realizado de forma anônima ver Côté (2014) e sobre a implantação de feedback dialogado Ho; Savignon (2007).

${ }^{6}$ Inicialmente o envio da produção escrita era realizado via e-mail (software de processamento de textos Word), mas tem migrado para o uso do recurso online Googledocs devido a versatilidade dessa ferramenta. Isso reflete um movimento de pesquisas recentes usando Googledocs (por exemplo, LEANDRO; WEISSHEIMER, 2017) que têm feito uso desta ferramenta também na escrita colaborativa, diminuindo o problema de incompatibilidade de versões do Word.

${ }^{7}$ A tabela de comentários foi adaptada a partir da tabela apresentada em Figueiredo e Rigonato (2017).
} 
Tabela 1 - Indicações para o feedback indireto

Faça anotações no texto, como vimos em sala usando a legenda abaixo.

XXXXX - (azul claro) palavra inadequada / ou sobrando

XXXXX - (amarelo) tempo verbal / concordância singular-plural

$X X X X X-($ cinza) ordem

$X X X X X$ - (vermelho) ortografia

$X X X X X-($ roxo) falta uma palavra

Faça também comentários em relação ao/à:

\section{Conteúdo}

Veja se o título está apropriado ao texto, se as ideias estão claras, se as ideias estão relacionadas ao tópico, se as ideias não estão repetidas etc.

Organização

Veja se o texto tem começo, meio e fim. Veja se as ideias estão organizadas de forma coerente e lógica, se os parágrafos estão bem desenvolvidos e ordenados, etc.

Fluência

Observe os sinais de pontuação, uso de letras maiúsculas (adjetivos pátrios, dias da semana, por exemplo) etc.

Fonte: o autor.

Em um segundo momento, após pedir a produção do segundo texto (ver modelo no anexo A), mas antes de enviá-los para a apreciação pelos pares, uma atividade de feedback foi realizada em sala de aula como forma de treinamento. O professor apresentou uma breve passagem textual produzida por um/a aluna/o de um semestre anterior - com todo sinal de identificação da/o autor/a removido - projetada no quadro e, com cópias desse texto em mãos, individualmente, os alunos deveriam assinalar pontos que poderiam ser melhorados e preencher o formulário para o feedback por pares. É importante ressaltar que eles estavam nesse momento trabalhando como revisores e deveriam apontar como a/o autor/a do texto analisado poderia melhorá-lo em uma versão final.

$\mathrm{Na}$ sequência, em pares eles compararam seus apontamentos e o treinamento terminou com a discussão das ideias no grande grupo. É imprescindível ressaltar que as críticas devem ser construtivas; trabalhar frases úteis ao oferecer feedback com os aprendizes é normalmente um ótimo exercício nesse momento. Nessa mesma linha, tal momento é uma oportunidade para alunos exercitarem de forma significativa estratégias de polidez em inglês. A opção pelo feedback dialogado oportuniza a reflexão de como o uso de determinadas expressões tende a diminuir conflitos na interação. Nessa mesma aula, o professor indicou que eles receberiam o texto de um/a colega com o formulário de feedback e a legenda de cores (ver tabela 1) por e-mail e deveriam realizar o feedback de forma semelhante ao do primeiro texto e enviá-lo para o professor.

Cabe ressaltar ainda que o uso exclusivo do inglês nas interações dialogadas não parece ser uma medida que se justifica pedagogicamente tendo em vista complexos aspectos metalinguísticos que podem emergir na interação. Zaccaron, Xhafaj e D’Ely (2019) sugerem 
que a imposição do inglês como língua de interação pode vir a inibir a contribuição de alguns estudantes. Tais discussões podem representar um desafio para a/o estudante de língua adicional inclusive na sua língua materna (van Compernolle, 2015). Dessa forma, encorajo o uso do inglês na interação, mas dependendo do contexto da turma o uso do português pode ser uma ferramenta mais adequada para tal fim.

Variações possíveis na implementação do feedback por pares

Ao receber as produções textuais, a/o professor/a deve manter os dados em uma planilha para ter o controle de quem está corrigindo o texto da/o colega. Independentemente do critério de escolha para a distribuição dos textos (no caso desse relato a distribuição foi aleatória), é importante que ele fique claro para os estudantes.

Outro procedimento importante a ser adotado pela/o professor/a nesse ponto, e que pode ter um impacto no foco do feedback fornecido, é adicionar as tabelas (ver tabela 1) aos textos como exposto no presente relato. Uma vez que as tabelas são copiadas para os textos pela/o professor/a e os dados dos autores e revisores são registrados, os textos estão prontos para serem enviados para os revisores (pares). Baseado na minha experiência, ao não utilizar a tabela adaptada de Figueiredo e Rigonato (2017) no passado, percebi que alunos focaram sua atenção quase de forma exclusiva em aspectos de forma ao prover feedback, similar ao que foi registrado por Côté (2014), deixando de lado aspectos relevantes do gênero textual (organização e conteúdo, por exemplo). Recomendo o uso da tabela ou ferramenta similar a fim de lembrar os alunos que o feedback não se resume à forma.

Esses são os passos básicos para a implementação do feedback por pares na aula de língua adicional. A partir deste ponto é possível seguir diversos caminhos. É possível trabalhar com o feedback por pares anônimo, por exemplo. Para tanto, uma vez que a primeira versão de um texto é recebida pela/o professor/a, ela/e pode remover as informações pessoais do arquivo (neste caso, é vital manter a tabela com as informações de quem está corrigindo o texto) e enviá-lo para outra/o aluna/o dar o feedback. Pode-se também trabalhar de forma dialogada (FIGUEIREDO; RIGONATO, 2017). Após o feedback ser enviado para a/o professor/a, ele pode ser impresso e discutido em sala de aula pelos pares a fim de maximizar as potencialidades dessa atividade através de diálogos colaborativos (SWAIN, 2000; SWAIN; BROOKS; TOCALLI-BELLER, 2002).

Na sequência, apresento algumas respostas da pesquisa em andamento sobre a eficácia e percepção do feedback por pares que dialogam com o método descrito. 


\section{A percepção dos participantes}

Ao final de cada semestre, os aprendizes que se voluntariam a participar da pesquisa em andamento respondem a um questionário online usando Googleforms, que contém perguntas abertas e fechadas, com o objetivo de compreender a percepção dos alunos em relação ao processo de feedback por pares. Para esse recorte, foram analisados 20 questionários, sendo 10 participantes de um grupo que trabalhou com feedback anônimo e 10 de um grupo que trabalhou com feedback dialogado. A análise qualitativa das respostas permitiu mapear algumas áreas de convergência das percepções individuais que são exemplificadas e discutidas na sequência. Alguns posicionamentos dos participantes ${ }^{8}$ são também apresentados.

Sobre o uso da tabela com os códigos coloridos para apontar aspectos a serem melhorados, a grande maioria dos comentários foi positiva, conforme exemplificado pelos excertos abaixo.

Gus: “As cores diferenciadas ajudam bastante na compreensão do tipo de erro cometido."

Jana: "Achei este tipo de correção interessante e criativo, isso porque destaca a parte do texto em que você precisa corrigir e te diz o porque está errado, mas ao mesmo tempo, não é uma resposta direta."

Andressa: "É uma boa ideia, tive um pouco de dificuldade no início por não estar familiarizada com ela."

No total, 17 dos 20 estudantes demonstraram uma atitude positiva em relação à função da tabela para correção, como apontaram Gus e Jana. O aspecto negativo parece estar ligado à novidade no seu uso (conforme aponta Andressa), que demanda o movimento de alternância entre texto e tabela. Tal posicionamento indica que o tempo para familiarização da atividade foi curto.

Apesar de a base teórica interacionista possibilitar o fundamento do uso do feedback por pares tanto para a melhoria de um texto quanto para a aprendizagem de LA (BITCHENER, 2012), esse processo não acontece sem desafios. Em resposta ao processo de revisão, alguns alunos destacaram não possuírem conhecimento suficiente para prover tal feedback.

Alisson: "Eu me sinto desconfortável sobre analisar textos em inglês pois não me considero exatamente fluente em gramática. Tive que me forçar a buscar erros, pois o texto estava bem

\footnotetext{
${ }^{8}$ Os nomes aqui apresentados foram escolhidos pelos participantes a fim de garantir a confidencialidade da pesquisa.
} 
compreensível para mim."

Taylor: "Gostei de ler o texto de outro colega, mas não de corrigi-lo. Não me sinto apta a corrigir algo no nível que estou em processo de aprendizagem."

Ju: “Acho que o colega não está apto a me corrigir, pois ainda está aprendendo."

Ao mesmo tempo que houve uma percepção positiva em ler o texto de um/a colega a posição de Taylor exemplifica uma resposta recorrente - em consonância com a literatura da área (FIGUEIREDO; RIGONATO, 2017; HO; SAVIGNON, 2007), que ressalta o benefício da exposição a diferentes estilos de escrita, também houve algumas respostas que indicam insegurança em prover o feedback, exemplificadas nos excertos retirados das respostas dos participantes Alisson e Ju. Vale ressaltar que muitas vezes essa insegurança está relacionada a aspectos da forma e não do conteúdo, conforme a observação de Alisson, que indica um possível foco principal de muitos alunos a aspectos linguísticos de forma, apesar de o treinamento para fornecer feedback ter focado também no conteúdo. Percebe-se, ainda, uma visão cristalizada que iguala feedback à busca por erros.

Da mesma forma, é possível perceber uma certa resistência a essa forma de feedback em algumas respostas, isso representa um desafio para a/o professor/a. Diversas respostas tocaram na questão da diferença entre dar e receber o feedback, como visto na resposta de Steven Universe.

Steven Universe: "É um exercício que ao meu ver vale muito a pena para o "colega" que corrige. Porém, para quem recebe a correção talvez não seja tão efetivo dado que de modo geral o "colega" não possui tanta credibilidade. Isto de modo algum é uma crítica aos companheiros de classe. Me coloco também incluso neste pacote. Ocorre, entretanto, que em certos questionamentos quanto a correção, as dúvidas aumentam ainda mais."

Tal posicionamento questionando a validade do feedback fornecido pelo par, também percebido na resposta de Ju, pode ser trabalhado através do feedback dialogado. É um fato estabelecido na literatura da área que muitos participantes preferem a resposta direta imediata (CHANG, 2016), que consideram certa, e tal posicionamento provavelmente reflete diferenças individuais de aprendizagem e crenças pré-estabelecidas. No entanto, é interessante perceber que mesmo nessa opinião aparentemente negativa sobre o feedback por pares se identifica o potencial de tal prática, uma vez que Steven Universe ressalta o processo de revisão do texto de um colega como um exercício interessante de reflexão. 0 feedback dialogado oferece a oportunidade de conversar com o colega e questionar possíveis pontos de incerteza, nesse momento os colegas perguntam o porquê de tal apontamento e não raro quem proveu o feedback indica a pesquisa que fez sobre tal ponto.

Em relação aos posicionamentos positivos sobre este tipo de feedback destacam-se a 
seguir.

Emily: "Ajudou no aumento do vocabulário e me permitiu ver como outras pessoas escrevem seus textos de formas diferentes da minha, com novas ideias e possibilidades."

Irmão do Joréu: "Gera a possibilidade de discussão, o que a meu ver é sempre positivo e auxilia na integração da equipe."

Gus: "Traz o benefício de despertar uma leitura crítica quanto aos aspectos gramaticais dado que se trata de um texto muito mais passível a erros que redações de jornais ou literatura de um modo geral."

Karol: "O benefício é o aprendizado que tive ao tentar corrigir o writing do colega, pois fui pesquisar as melhores maneiras de reescrever o texto, buscando novas formas."

Ter a possibilidade de ler o texto de um/a colega é um aspecto amplamente ressaltado (CÔTÉ, 2014; FIGUEIREDO; RIGONATO, 2017; SILVA, 2013). É possível perceber os benefícios apontados por Ho; Savignon (2007) e Shrum; Glisam (2009) - que ressaltam o aspecto positivo de perceber erros e acertos alheios - nas respostas acima, que apontam a discussão e a possibilidade de ver diferentes estilos de escrita. É possível também apreender reflexões metalinguísticas e metacognitivas nas respostas de Gus e Karol, que analisam não apenas a língua, mas o próprio processo de aprendizagem. Como apontado por Sinclair (2000), tais reflexões são etapas necessárias para o desenvolvimento da autonomia e parece haver evidência de que desenvolver o feedback por pares pode vir a fomentar a/o escritor/a autônoma/o não apenas na língua adicional.

Em relação ao posicionamento de Emily, que indicou o benefício de ler um texto com formas e ideias diferentes da sua, percebe-se que a estudante valorizou a oportunidade de ler um texto autêntico produzido por um/a colega, como aponta Figueiredo e Rigonato (2017). Ademais, o foco da sua atenção esteve voltado tanto para a forma (vocabulário) como para a mensagem (ideias/possibilidades), aspecto importante para o desenvolvimento na LA (SWAIN, 2000).

Finalmente, enquanto autor desse relato, minha percepção é que o saldo da implantação do feedback por pares na aula de língua adicional é positivo, ou pelo menos tem sido positivo em minhas experiências até então. Por um lado, a/o professor/a não reduz seu trabalho, muito pelo contrário, pois para supervisionar o processo são requeridos tempo e atenção. Por outro lado, por compreender que a escrita não é apenas um mero produto, o desenvolvimento da atividade de feedback traz consigo elementos positivos - a autonomia, por exemplo - para o desenvolvimento tanto da/o escritor/a quanto da/o aprendiz em língua adicional. Há também a divisão de responsabilidades, como aponta Liu e Edwards (2018), e uma participação mais ativa dos estudantes no seu processo de aprendizagem através da reflexão sobre o mesmo. 
Considero, ainda, que é mais positivo para a/o aprendiz trabalhar a reescrita de um mesmo texto a fim de desenvolvê-lo - na forma de um processo, como recomendam Hyland e Hyland (2006) - do que produzir uma série de textos curtos sem a possibilidade de reescrita, por exemplo. A escrita como processo é uma oportunidade extra para a reflexão metacognitiva e metalinguística na aula de LA. É preciso tentar quebrar a ideia cristalizada de que textos devem ser escritos e revisados rapidamente de forma mecânica (SILVEIRA, 1999) e apenas pela/o professor/a.

\section{Considerações finais}

Esse relato teve como objetivo principal partilhar a experiência do autor na implantação do feedback por pares na aula de inglês como língua adicional, um movimento que faz parte de uma pesquisa longitudinal. Ao invés de apresentar modelos prontos, esperase que as discussões aqui levantadas instiguem professoras/es de LA a utilizar o feedback por pares e sirvam de suporte para a implantação de atividades semelhantes que levem em consideração características específicas de cada contexto.

O feedback por pares pode ser implantado na aula de língua adicional. Como relatado, há desafios nesse percurso: o tempo curto para a familiarização com essa forma de feedback em um curso de inglês, a resistência de alguns alunos ao processo e a noção generalizada de que feedback serve apenas para apontar erros. Por outro lado, os alunos dessa pesquisa indicaram apreciar a oportunidade de: ler um texto autêntico produzido pela/o colega (FIGUEIREDO; RIGONATO, 2017), refletir sobre as escolhas linguísticas (tanto as suas quanto da/o colega) e a pesquisa necessária para a/o colega prover e receber o feedback. Desse modo, o papel de pesquisador/a, apontado por Beaufort (2000), firma-se como um ponto relevante para o uso do feedback por pares, pois efetivamente desloca-se o papel de expert normalmente atribuído à/ao professor/a para a/o aprendiz.

Cabe salientar, ainda, que essa é uma das principais razões para se implantar o feedback por pares. Tal movimento vai além da simples correção do texto e muda a dinâmica no processo de aprendizagem (FIGUEIREDO; RIGONATO, 2017; SILVA, 2013). Foi possível inferir, a partir das respostas dos participantes, que o papel de revisor/a despertou a atenção para o processo da aprendizagem em LA. É preciso que sejam propiciados à/ao estudante momentos de reflexão contextualizada como esse, pois como aponta Sinclair (2000), oportunidades de reflexão metacognitiva fazem parte do desenvolvimento da autonomia.

\section{Referências}

BEAUFORT, A. Learning the Trade: A Social Apprenticeship Model for Gaining Writing Expertise. Written Communication, v. 17, n. 2, p. 185-223, 2000. 


\section{https://doi.org/10.1177/0741088300017002002}

BITCHENER, J. A reflection on 'the language learning potential' of written CF. Journal of Second Language Writing, v. 21, p. 348-363, 2012. https://doi.org/10.1016/j.jslw.2012.09.006

BORG, S.; AL-BUSAIDI, S. Learner Autonomy: English Language Teachers' Beliefs and Practices. London: British Council, 2012.

CHANG, C. Y. Two decades of research in L2 peer review. Journal of Writing Research, v. 8, n. 1, p. 81-117, 2016. https://doi.org/0.17239/jowr-2016.08.01.03

CÔTÉ, R. A. Peer Feedback in Anonymous Peer Review in an EFL Writing Class in Spain. Gist Education and Learning Research Journal, v. 9, p. 67-87, 2014.

FIGUEIREDO, F. J. Q. Aprendendo com os erros: uma perspectiva comunicativa de ensino de línguas. Goiânia: Editora da UFG, 2002.

FIGUEIREDO, F. J. Q.; RIGONATO, L. G. N. A utilização de um formulário de orientação na correção com os pares: um estudo com alunos do nível intermediário de um curso de línguas. Caminhos em Linguística Aplicada, v. 16, n. 2, p. 156-178, 2017.

FIGUEIREDO, F. J. Q.; VIEIRA, P. F. M. D. A correção dialogada entre professora e alunos: os benefícios dessa ferramenta colaborativa no processo de revisão de textos escritos em inglês. In: TOMITCH, L. M. B.; HEBERLE, V. M. (org.) Perspectivas atuais de aprendizagem e ensino de línguas. 1. ed. Florianópolis: LLE/CCE/UFSC, v.1, 2017. p. 153-200.

HO, M.; SAVIGNON, S. Face-to-face and computer-mediated peer review in EFL writing. CALICO Journal, v. 24, n. 2, p. 269-290, 2007. https://doi.org/10.1558/cj.v24i2.269-290

HOLEC, H. Autonomy in foreign language learning. Oxford: Pergamon, 1981.

HYLAND, K.; HYLAND, F. Feedback on second language students' writing. Language Teaching, v. 39, n. 2, p. 83-101, 2006. https://doi.org/10.1017/s0261444806003399

LEANDRO, D. C.; WEISSHEIMER, J. Escrita colaborativa de flash fiction e aprendizagem de Inglês como L2: o desenvolvimento da acurácia gramatical e densidade lexical. Raído, v. 11, n. 27, p. 323-337, 2017. https://doi.org/10.30612/raido.v11i27.5658

LIU, J.; EDWARDS, J. Peer response in second language writing classrooms. 2. ed. Ann Arbor, MI: University of Michigan Press, 2018.

LONG, M. Second language acquisition and task-based language teaching. Malden, MA: Wiley Blackwell, 2015.

MARTINS, A.; REIS, E. C. (2015). Internacionalização na UFSC: Análise do Programa Inglês Sem Fronteiras e do Curso Extracurricular de Inglês. In: XV Colóquio Internacional de Gestão Universitária (CIGU). Mar del Plata (Anais). p. 1-14.

SINCLAIR, B. Learner autonomy: The next phase? In: SINCLAIR, B.; MCGRATH, I.; LAMB, T. (Eds.), Learner autonomy, teacher autonomy: Future directions. Harlow: Longman, 2000. p. 414.

SILVA, S. L. A. escrita colaborativa e as novas tecnologias: relato de experiência. Domínios de Lingu@gem, v. 7, n. 1, p. 245-262, jun. 2013.

SILVEIRA, R. The relationship between writing instruction and EFL students' revision processes. Linguagem \& Ensino, v. 2, n. 2, p. 109-127, 1999. 
SHIGUNOV NETO, A.; MACIEL, L. S. B. Refletindo sobre o passado, o presente e as propostas futuras na formação de professores. Revista Internacional de Formação de Professores, [S.I.], p. 172-186, mai. 2016.

SHRUM, J.; GLISAN, E. Teacher's Handbook: Contextualized Language Instruction. 4. ed. Cengage Learning, 2009.

STORCH, N. Collaborative writing: Product, process, and students' reflections. Journal of Second Language Writing, v. 14, n. 3, p. 153-173, 2005.

SWAIN, M. The output hypothesis and beyond: Mediating acquisition through collaborative dialogue. In: LANTOLF, J. (org.) Sociocultural Theory and Second Language Learning. Oxford: Oxford University Press, 2000.

SWAIN, M.; BROOKS, L.; TOCALLI-BELLER, A. Peer-peer dialogue as a means of second language learning. Annual Review of Applied Linguistics, v. 22, p. 171-185, 2002. https://doi.org/10.1017/S0267190502000090

VAN COMPERNOLLE, R. A. Interaction and second language development: A Vygotskian perspective. Amsterdam: John Benjamins, 2015.

WEININGER, M. Continuamos do aquário em direção ao mar aberto? Mais mudanças no papel do professor e do aluno. In: LEFFA, V. J. O professor de línguas estrangeiras: construindo a profissão. 2. ed. Pelotas: EDUCAT, 2008. p. 45-74.

ZACCARON, R.; XHAFAJ, D.; D’ELY, R. "Só mais um minutinho, teacher": planejamento estratégico colaborativo e individual para tarefas orais em L2 em uma escola pública. Ilha do Desterro A Journal of English Language, Literatures in English and Cultural Studies, v. 72, n. 3, p. 401-426, 2019. https://doi.org/10.5007/2175-8026.2019v72n3p401

Recebido em: 30/09/2019.

Aceito em: 05/03/2020. 


\section{Anexo A}

Hi everyone,

Please find below the guidelines for your second writing.

Unit 10 dealt with predictions about the future, so I thought it would be nice that we

contextualise this topic and discuss our future (our country, state, city or local community) in this writing.

Think about ONE problem/situation and possible solutions for its development in the future.

The deadline for you to send ME the first draft (WORD doc or equivalent, NO PDF. You need to attach the file to the email) is $\mathbf{X X / X X X ~ ( X X X d a y ) . ~}$

This is a pros and cons essay.

I expect this text to have:

- around 200 words;

- a title that reflects its content;

- An introduction/ main points/conclusion. You may write it in 3 paragraphs if that is easy for you to organise it.

You need to introduce the topic, present pros and cons related to the chosen issue and, finally, conclude taking a stance based on the facts you brought.

- some arguments to back your opinion (not only: "I think so")

- that you show your opinion (please don't write 'my opinion is..'.

There are other ways to do so.)

There is an EXAMPLE of pros and cons essay attached.

The style should not be very formal and I really want to hear your voice through the text.

Remember that I am going to send the file to a peer and you will receive your writing back for possible revisions in the next ten days.

Best.

$\mathrm{XXXXX}$ 